\title{
Familial Study of Paracentric Inversion in Chromosome 3p
}

\author{
Sandra Alves Peixoto Pellegrini ${ }^{1^{*}}$, Maria Cecilia Menks Ribeiro ${ }^{1,2}$, \\ Evelyn Kahn ${ }^{3}$, Gabriela Leal de Barros ${ }^{1}$, Mauricio Assis Rodrigues ${ }^{1}$, \\ Marcelo de Paula Coutinho ${ }^{3}$ and Márcia Goncalves Ribeiro ${ }^{4}$ \\ ${ }^{1}$ Cytogenetics Laboratory - Martagão Gesteira Pediatric Institute - Federal University of Rio \\ de Janeiro, Rio de Janeiro, Brazil. \\ ${ }^{2}$ Department of Celular Biology, Cytogenetics Laboratory, Embriology and Genetics- Federal \\ University of Santa Catarina, Florianópolis, Brazil. \\ ${ }^{3}$ Clinical Genetics Service, Reference Center for Child and Adolescent - CRTCA, Campos \\ dos Goytacases, Brazil; Datagenno Interactive Research Ltda, Rio de Janeiro, RJ, Brazil. \\ ${ }^{4}$ Medical Genetics Service - Martagão Gesteira Pediatric Institute - Federal University of \\ Rio de Janeiro, Rio de Janeiro, Brazil.

\section{Authors' contributions} \\ This work was carried out in collaboration between all authors. Author SAPP substantial \\ contributions to research design; analysis and interpretation of data; drafting the paper and \\ revising it critically. Author MCMR analysis and interpretation of data; revising the paper \\ critically and approval of the submitted and final versions. Author EK drafting the paper and \\ revising clinically the patients and relatives. Author GLB drafting the paper, author MAR \\ substantial contributions to research design. Author MPC drafting the paper and revising \\ clinically the patients and relatives. Author MGR substantial contributions to research design; \\ analysis and interpretation of data; drafting the paper and revising it critically and approval of \\ the submitted and final versions. All authors read and approved the final manuscript.
}

Research Article
Received $28^{\text {th }}$ August 2012 Accepted $17^{\text {th }}$ January 2013 Published $28^{\text {th }}$ February 2013

\section{ABSTRACT}

Aims: To describe the familial occurrence of paracentric inversion of chromosome 3. Presentation of Cases: Patient 1: Female, Caucasian, born in Southeast of Brazil, 7 years old. Born at term and asphyxia. Developmental delay; aggressive behavior and tendency toward isolation. Prominent forehead, discrete epicanthal folds, down-slanting palpebral fissures, long philtrum and hypermobility of the four limbs. Karyotype: 
46,XX,inv(3)(p13p25). Patient 2: Female, Caucasian, born in Northeast of Brazil, 3 years old. Born prematurely by cesarean section, pelvic presentation and asphyxia. Severe developmental delay. Microcephaly, bilateral convergent strabismus, epicanthal folds, wide nasal bridge, micrognathia, high arched palate and nasolabial hemangioma, low set ears, hypoplastic nipples, nucal café-au-lait spots, deep plantar fold. Dysgenesis of the corpus callosum. Karyotype: 46,XX,inv(3)(p13p25). Patient 3: Male, Caucasian, born in Southeast of Brazil, 5 years. Born at term, by cesarean section, cephalic presentation. Developmental delay and flexor spasms. Dolichocephalic skull, prominent forehead, ocular hypertelorism, epicanthal folds, disproportioned and low set ears, single palmary crease in the right hand, large and elongated thumbs, hypotonia, and recurrent acute otitis. Karyotype: 46,XY,inv(3)(p13p25).

Discussion: Patients presented developmental delay and dysmorphic features, but the relatives that presented the same inversion were asymptomatic. Carriers seem to have a normal reproductive fitness, without differences between males and females.

Conclusion: The chromosomal rearrangements, especially balanced chromosomal alterations provide an opportunity to broaden the understanding of the structure and functional organization of chromosomes and to offer better genetic counseling for the families.

Keywords: Balanced rearrangement; paracentric inversion; chromosome 3p; dysmorphic features; familial inversion; family study; chromosomal imbalance; karyotypephenotype correlation.

\section{INTRODUCTION}

Since the introduction of banding techniques for cytogenetics studies, the majority of laboratories have recorded structural rearrangements visible using moderate levels of banding [1]. The detection of families with balanced rearrangements is an opportunity to highlight the plasticity of the genome and its phenotypic effect, making the opportunity to provide an individualized family counseling possible [2].

An inversion can be imagined as a section of a chromosome being taken out, turned through $180^{\circ}$ and inserted back in its original position. The position of the breakpoints identify it as paracentric or pericentric [3]. In humans, pericentric inversions are found with a frequency of $1-2 \%$. The incidence of paracentric inversion is much lower with values ranging from $0.002 \%$ to $0.049 \%$ [4]. A French Collaborative Study [5], evaluated 304 cases and reported the frequency of paracentric inversion as being ten times lower than that of pericentric inversion, which is more easily detected. Paracentric inversions were described in nearly all chromosomes, from the longest to the shortest. Chromosomes 3, 6, 7, 11, 14 and 15 are the most frequently represented and the most commonly identified inversions were $3(\mathrm{p} 13 \mathrm{p} 25)$, 6(p12p23), 6(p12p25), 7(q11q22), 11(q21q23), and 14(q13q24), [7,8].

The majority of paracentric inversions are familial, ranging from 66 to $71 \%[9,10]$. Inversions were detected in routine cytogenetic studies in patients with phenotypic changes, and in prenatal diagnosis $[7,8,1]$; the main indications of prenatal diagnosis reported by Madan et al [7] were advanced maternal age, neural tube defect and familial studies.

In this study we describe the familial transmission of a paracentric inversion on the short arm of chromosome 3 in three unrelated families. This study was submitted to and approved by the Research Ethical Committee of The Martagão Gesteira Pediatric Institute (IPPMG). 


\section{PRESENTATION OF CASE}

The three index patients and their relatives were examined by the staff of Medical Genetics Service and referred for cytogenetic investigation due to developmental delay and dysmorphic features on index patients.

\subsection{Patient 1 (PSS)}

Female, Caucasian, born in Rio de Janeiro (Southeast of Brazil), 7 years old at the time of examination. The patient is the second child of non-related couple, both born in Rio de Janeiro. At the time of the child birth the mother was 24 years old and the father 31 years old. The mother was healthy unlike the father who was an alcoholic person and presented cardiopathy and neuropsychiatric problems. The maternal grandparents were from Paraiba (Northeast of Brazil) and paternal grandparents are from the Northeast region of Brazil (non specified state). The patient was born at term following an extended natural labor in which perinatal asphyxia was suspected. At birth the patient was $2.800 \mathrm{~g}(P=10)$ and $47 \mathrm{~cm}(P=10)$. In the first post-natal years the patient displayed significant delay in language skills (the first words were pronounced after five years of age), poor learning skills at school due to cognitive deficit and absence of sphincter control. However, no motor delay was observed. The patient also showed aggressive behavior and a tendency toward isolation. At clinical examination, facial dysmorphism (prominent forehead, discrete epicanthal folds, downslanting palpebral fissures, long philtrum) and hypermobility of the four limbs were detected. Brain CT scan was normal and karyotype was $46, X X$,inv(3)(p13p25). The same inversion was presented in the patient's sister and no visible difference between the patient's paracentric inversion and her sister's was detected (Fig. 1 - family 1). Karyotype of her mother and her brother was normal, her father wasn't evaluated because he was dead at that time.

\subsection{Patient 2 (IMMN)}

Female, Caucasian, born in Pernambuco (Northeast of Brazil), 3 years old at the time of examination. She was the second child of non-related, healthy couple, both born in Rio de Janeiro. Maternal and paternal grandparents were from Pernambuco too. At the time of the child birth the mother was 35 years old and the father 33 years old. During the first trimester of pregnancy the mother presented vaginal bleeding and oligohydramnios was detected on the fifth month of pregnancy. The patient was preterm (36 weeks of Gestational Age) born by cesarean section, pelvic presentation and APGAR index of 2 and 6 . Meconium aspiration was required. The newborn presented jaundice and, intraventricular bleeding. These conditions resulted in a 20-day stay at the Neonatal Intensive Care Unit. At birth the patient was 2.600g (P25 - 50) and 44cm (P10 - 25). In the first post-natal years the patient showed severe developmental delay including difficulty in language acquisition, motor and mental retardation. Clinical examination revealed microcephaly, bilateral convergent strabismus, epicanthal folds, wide nasal bridge, micrognathia, high arched palate and nasolabial hemangioma, low set ears, hypoplastic nipples, nucal café-au-lait spots, deep plantar fold. The ophthalmologic evaluation revealed coloboma of the left optic nerve and severe myopia. Brain CT scan showed ventricular dilation with major parallelism suggesting dysgenesis of the corpus callosum. Karyotype was 46, XX, inv(3)(p13p25); the same inversion was presented in the patient and her sister, her mother, and maternal grandmother and no visible difference between patient's paracentric inversion and her mother or grandmother maternal was detected (Fig. 1 - family 2). 


\subsection{Patient 3 (BPSS)}

Male, Caucasian, born in Rio de Janeiro, 5 years old at the time of examination. The patient is the second child of healthy, unrelated couple. His mother is from Maranhão (Northeast of Brazil) and his father and paternal grandparents are from Pará (North of Brazil). At the time of the child birth the mother was 28 years old and the father, 29 years old. The patient was born at term, by cesarean section, cephalic presentation. At birth the patient was $2.750 \mathrm{~g}$ $(P=10)$ and $47 \mathrm{~cm}(P=10)$. The clinical examination revealed developmental delay, no language acquisition and flexor spasms. The patient also displayed dolichocephalic skull, facial dysmorphism (prominent forehead, ocular hypertelorism, epicanthal folds, disproportioned and low set ears, single palmary crease in the right hand, large and elongated thumbs), hypotonia, and recurrent acute otitis. The ophthalmologic evaluation and brain CT scan did not reveal any abnormalities. The patient's sister presented total bilateral syndactyly of the second and third toes. Karyotype was 46, $X Y$, inv(3)(p13p25), the same inversion was presented in the patient, his sister, and his father and no visible difference was detected between patient's paracentric inversion and the three family members (Fig. 1 family 3). The patient died at 9 years of age due to central nervous system disease and infectious complication.

\section{CYTOGENETIC STUDY}

Routine chromosome preparations were made from peripheral blood lymphocytes after $72 \mathrm{~h}$ in culture with RPMI-1640 supplemented with $20 \%$ fetal bovine serum and phytohemagglutinin (PHA). The $\mathrm{G}$ band technique (300-400 bands) was applied to analyze 20 cells from each patient and their relatives. The chromosomes were classified according ISCN 2009 [11]. 


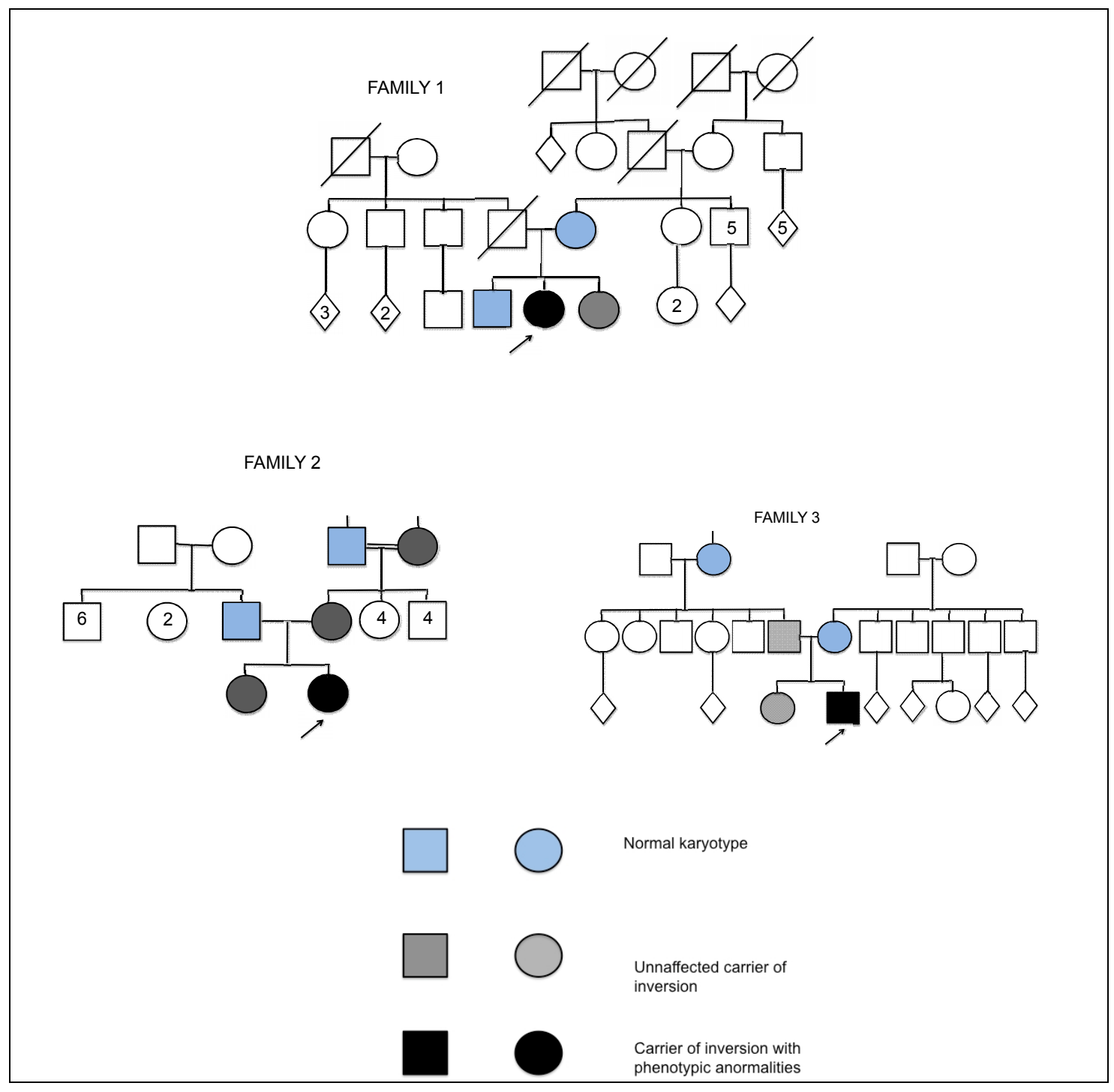

Fig. 1. Heredogram of the families with paracentric inversion of chromosome 3 

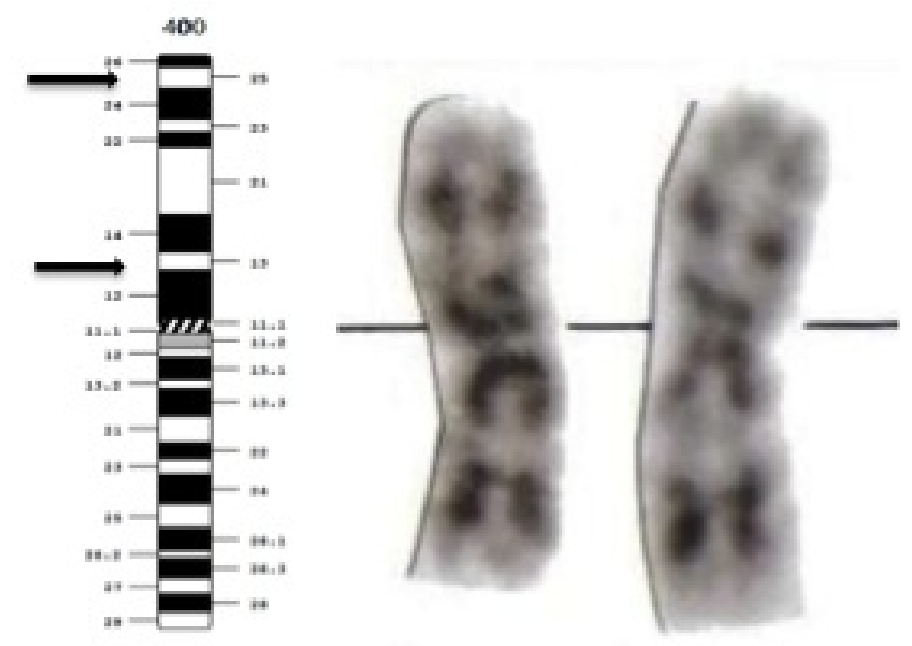

Fig. 2. Ideogram of chromosome 3 with arrows in the breakpoints and partial karyotype with the $3 p$ inversion. The left chromosome is the normal chromosome and the right is the chromosome with the inversion

In the three families there was a segregation of a paracentric inversion on the short arm of chromosome 3, with breakpoints in p13 and p25 (Fig. 2). A total of eight inversion carriers were identified, of which only 3 had phenotypic changes (Fig. 1).

\section{DISCUSSION}

In this study, we described the familiar occurrence of the same paracentric inversion of chromosome 3 with breakpoints at p13p25 in three unrelated patients. Including the families of the present study there were 25 patients with inversion of chromosome $3 p$; among them, 20 were familial and 4 of unknown origin, and one de novo. Considering the relatives, there is a total of 53 individuals with chromosome $3 p$ inversion.

In a search of unbalanced gametes in inversion carriers, Anton et al. [4] verified that the size of inverted segments and their proportion in the chromosome are two parameters closely related with the incidence of recombination. Their results suggest that the production of a significant level of unbalanced gametes would require a minimum inversion size of $100 \mathrm{Mpb}$ and the inversion of at least $50 \%$ of the chromosome. In these families the inversion size was estimated in $60 \mathrm{Mpb}, \sim 30 \%$ of chromosomal length and recombination probably didn't occur during the gametogenesis. In these families and the segregation of inversion was without recombination.

Most of inversions are assumed to have unique breakpoints [12]. The recurrence of paracentric inversion suggests that specific regions may undergo increased rates of breakage and recombination [8]. The review of 446 cases of paracentric inversions in human inversions revealed that the inv $(3)(\mathrm{p} 13 \mathrm{p} 25)$ is a commonly identified inversion [8]. Table 1 shows the type of inversion, the indication for the investigation and the familial occurrence of the 22 published cases and our three cases. 
Pettenati et al [8] analyzed 446 cases of chromosomal paracentric inversion, which $66 \%$ were of inherited inversion, while less than $10 \%$, were de novo inversion. De novo inversions were more likely to be associated with the presence of mental retardation and congenital malformations (32\%) than inherited ones (22\%). In our three cases, familial inheritance was of $100 \%$. Youings et al [1] verified in 129 probands de novo inversion in $8.5 \%$ while $51.2 \%$ were inherited from the father and $40.3 \%$ from the mother. Analysis of the breakpoint regions identified no obvious predisposing factors for the breakage in the DNA sequence [12].

We would like to call attention to the similarities revealed in our patients: developmental delay and dysmorphic features (prominent forehead, epicanthal folds and low set ears). Madan et al [7] and Pettenati et al [8], described strong association between general inversion and mental retardation and /or malformations (22.2\%); similar to related in the literature and the majority of inherited new paracentric inversions were identified incidentally $(85.2 \%)$. Nevertheless it is hard to establish a secondary phenotype based on these cytogenetic alterations. It is important to notice that we demonstrated that the abnormal children studied here show low chromosomal imbalance, which allowed the gestation to develop to term. Inversions may have long life spans and presumably the most frequent and widely distributed inversions have a more ancient origin, although there will be founder effects specific to particular regions or countries [12].

These balanced rearrangements were demonstrated to be responsible for the phenotype by different mechanisms such as gene disruption at the breakpoints, position effect or disturbance of parental imprinting [13]. Gijsbers et al [2], revaluating patients with equilibrated chromosomal alterations using array techniques, and detected an additional cryptic CNV (Copy Number Variation), in $61.5 \%$ of patients, suggesting that apparently balanced chromosomal rearrangements with abnormal phenotype are in fact imbalanced. Unfortunately, it was not possible to perform aCGH to search minor abnormalities because the follow-up was discontinued in all three studied cases. 
Table 1. Review of the chromosome 3 inversions cases, clinical data, breakpoints and familial and familial occurrences

\begin{tabular}{|c|c|c|c|c|}
\hline Author(s) & Probands & Clinical data & Breakpoints & $\begin{array}{l}\text { Familial occurrence of the } \\
\text { inversion }\end{array}$ \\
\hline $\begin{array}{l}\text { Fryns and Van den Berghe } \\
\text { [14] }\end{array}$ & o, 3 years & Slight developmental delay & p13p25 & $\begin{array}{l}\text { Mother, maternal } \\
\text { grandmother and uncle }\end{array}$ \\
\hline \multirow[t]{3}{*}{$\begin{array}{l}\text { Fryns and Van den Berghe } \\
\text { [15] }\end{array}$} & o, 7 years & $\begin{array}{l}\text { Slight developmental delay, growth } \\
\text { failure, divergent strabismus and } \\
\text { pectus excavatum }\end{array}$ & p13p25 & Mother \\
\hline & ๙, 30 years & $\begin{array}{l}\text { Wife with positive familial history of } \\
\text { neural tube defects; son with the } \\
\text { same inversion and normal } \\
\text { development }\end{array}$ & p13p25 & Son \\
\hline & $\delta$, fetus & $\begin{array}{l}\text { Prenatal diagnosis; maternal uncle } \\
\text { with spina bifida }\end{array}$ & p13p25 & Father \\
\hline Peters-Slough et al [16] & o, 4,5 years & $\begin{array}{l}\text { Short stature, normal intelligence } \\
\text { and psychomotor development. No } \\
\text { dysmorphic features. Maternal } \\
\text { history of epilepsy, use of } \\
\text { phenobarbital, carbamazepine, } \\
\text { diphenyl hydantoin, primidone and } \\
\text { ampletamyne during pregnancies } \\
\text { and three miscarriages }\end{array}$ & p13p25 & Mother \\
\hline Madan et al [7] & $\hat{\sigma}$, fetus & $\begin{array}{l}\text { Prenatal diagnosis: elevated levels } \\
\text { of serum alpha-fetoprotein }\end{array}$ & p11p21 & $\begin{array}{l}\text { Mother and maternal } \\
\text { grandfather }\end{array}$ \\
\hline Callen et al [17] & $\widehat{\partial}$, newborn & $\begin{array}{l}\text { Unusual facies, bilateral tight } \\
\text { calcaneo-valgus, hypermobile small } \\
\text { joints, systolic murmur, mild } \\
\text { glandular hypospadia }\end{array}$ & p21p25 & Father \\
\hline \multirow[t]{3}{*}{ Fryns et al [18] } & $\hat{\sigma}$, adult & Miscarriages & p13p25 & Grandmother \\
\hline & q, 36 years & $\begin{array}{l}\text { Genetic counseling: early death of } \\
\text { her first child }\end{array}$ & p13p25 & Unknown \\
\hline & $\widehat{o}$, adult & $\begin{array}{l}\text { Genetic counseling: an abnormal } \\
\text { child + one intrauterine death. } \\
\text { Actually she has one normal child }\end{array}$ & p13p25 & Brother, sister, and son \\
\hline
\end{tabular}




\begin{tabular}{|c|c|}
\hline \multirow{4}{*}{$\begin{array}{l}\text { French collaborative study } \\
\text { [5] }\end{array}$} & $\begin{array}{l}\lambda, 11 \text { years } \\
\delta, 2 \text { years }\end{array}$ \\
\hline & $\begin{array}{l}\text { q, fetus } \\
\text { o, abortion } \\
\text { o, adult }\end{array}$ \\
\hline & q, adult \\
\hline & $\widehat{\partial}$, adult \\
\hline Youings et al [1] & $\begin{array}{l}q \\
+ \\
+ \\
+ \\
q \\
q \\
q \\
0\end{array}$ \\
\hline \multirow{3}{*}{$\begin{array}{l}\text { Pellegrini et al (present } \\
\text { study) }\end{array}$} & $\uparrow, 13$ years \\
\hline & ㅇ, 5 years \\
\hline & $\lambda, 3$ years \\
\hline
\end{tabular}

TOTAL with normal karyotype and another normal child with the inversion Atrophic testes

Developmental delay, dysmorphic features (wide nasal bridge, ocular hypertelorism). Preterm infant, very low birth weight; his twin brother died in utero

Genetic counseling

Genetic counseling

Stillbirth

Husband with $\mathrm{t}(13 \mathrm{q} 14 \mathrm{q})$; two

miscarriages

Two recurrent miscarriages; wife with $\mathrm{t}(7 ; 12)$

Abnormal phenotype

Prenatal diagnosis

Abnormal phenotype

Abnormal phenotype

Prenatal diagnosis

Developmental delay and facial

dysmorphism

Developmental delay and facial

dysmorphism

Developmental delay and facial

dysmorphism

$\begin{array}{ll}\text { p13p25 } & \text { Mother } \\ \text { p13p25 } & \text { Mother }\end{array}$

p13p25 Mother

\begin{tabular}{|c|c|}
\hline p12p26 & Father \\
\hline p21p24 & Father \\
\hline p24p26 & $\begin{array}{l}\text { Mother, maternal } \\
\text { grandmother }\end{array}$ \\
\hline p24p26 & Unknown \\
\hline p24p26 & Unknown \\
\hline p13-p21 & Unknown \\
\hline p11-p21 & Father \\
\hline p12.3-p21.33 & Father \\
\hline p21-p25 & Mother \\
\hline p24.2-p25.3 & De novo \\
\hline p13p25 & Sister \\
\hline p13p25 & $\begin{array}{l}\text { Mother and maternal } \\
\text { grandmother }\end{array}$ \\
\hline $13 p 25$ & Father and sister \\
\hline
\end{tabular}




\section{CONCLUSION}

The chromosomal rearrangements, specially balanced chromosomal alterations provide an opportunity to broaden the understanding of the structure and functional organization of chromosomes. The findings described here once more demonstrate the necessity of using the conventional karyotyping together with molecular technique. The karyotyping is not an appropriate instrument for detecting abnormalities smaller than 5-10 Mb, and some molecular techniques like high-resolution array screening don't identify apparent equilibrated chromosomes, so it is important to use both techniques to investigate the breakpoints presented in equilibrated translocations and inversions [13]. Although most of the inversions are detected by routine analysis by chromosome banding, new methodologies can allow greater resolution in detection of imbalanc, that can elucidate the processes that determine the genotype-phenotype relationship, enabling more effective basis for genetic counseling / family counseling [2].

\section{CONSENT}

As the informed consent couldn't be obtained due to death and/or change of residence place the patients, the Ethics Committee of the Martagão Gesteira Pediatric Institute (IPPMG) approved the use of a Researcher Commitment Form to the collected data.

\section{ETHICAL APPROVAL}

This study was submitted to and approved by the Research Ethical Committee of The Martagão Gesteira Pediatric Institute (IPPMG), approved in December, $20^{\text {th }}, 2005$.

\section{ACKNOWLEDGEMENTS}

The authors are grateful to Dra Ivone Beatriz Otazu, Dra Monica Pereira and Dr Mauro Geller for their critical reading of the manuscript.

\section{COMPETING INTERESTS}

Authors have declared that no competing interests exist.

\section{REFERENCES}

1. Youings $\mathrm{S}$, Ellis $\mathrm{K}$, Ennis $\mathrm{S}$, Barber J, Jacobs $\mathrm{P}$. A study of reciprocal translocations and inversions detected by light microscopy with special reference to origin, segregation, and recurrent abnormalities. Am J Med Genet. 2004;126A:46-60.

2. Gijsber ACJ, Bosch CAJ, Daubers JG, Giroux O, Hansson K, Hilhorst-Hofstee Y, et al. Additional Cryptic CNVs in mentally retarded patients with apparently balanced karyotypes. Eur J Med Genet. 2010;53:227-33.

3. Cross I, Wolstenholme J. Chromosomes and their analysis. In: Rooney DE, editor. Human Cytogenetics Constitutional Analysis. $3^{\text {rd }}$ ed. Oxford: Oxford University Press, 2001.

4. Anton E, Blanco J, Egozcue J, Vidal F. Sperm studies in heterozygote inversion carriers: a review. Cytogenet Genome Res. 2005;111:297-304. Callen DF, Woollatt E, Sutherland GR. Paracentric inversions in man. Clin Genet. 1985;28(1):87-92. 
5. GROUPE DE CYTOGÉNÉTICIENS FRANÇAIS. Paracentric inversions in man: A French collaborative study. Ann Génét. 1986;29(3):169-76.

6. Madan K, Seabright M, Lindenbaum RH, Borrows M. Paracentric inversions in man. J Med Genet. 1984;21:407-12.

7. Pettenati MJ, Rao PN, Phelan MC, Grass F, Rao KW, Casper P,et al. Paracentric inversions in Humans: A review of 446 paracentric inversions with presentation of 120 new cases. Am J Med Genet. 1995;55(2):171-87.

8. Madan K. Paracentric inversions. Hum Genet. 1995;96:503-15.

9. Del Solar C, Uchida I. A identification of chromosomal abnormalities by quinacrinestaining technique in patients with normal karyotypes by conventional analysis. J Pediat. 1974;84:534-9.

10. Shaffer LG, Slovak ML, Campbell LJ, editors. ISCN 2009- An International System for Human Cytogenetic Nomenclature (2009). Basel: Karger; 2009.

11. Thomas NS, Bryant V, Maloney V, Cockwell AE, Jacobs PA. Investigation of the origins of human autossomal inversions. Hum Genet. 2008;123:607-16.

12. Schluth-Bolard C, Delibes B, Saltville D, Boute O, Cuisse JM, Sukno S, et al. Cryptic genomic imbalances in de novo and inherited apparently balanced chromosomal rearrangements : Array CGH study of unrelated cases. Eur J Med Genet. 2009;52:291-5.

13. Fryns JP, van den Berghe $H$. Familial paracentric inversion of the short arm of chromosome 3. Ann Genet. 1979;22:163-4.

14. Fryns JP, van den Berghe $\mathrm{H}$. Paracentric inversion in man: personal experience and review of the literature. Hum Genet. 1980;54:413-6.

15. Peters-Slough MF, Planteydt HT, Timmerman MJ, Vooren MJ. A familial paracentrics inversion in the short arm of chromosome 3: a case report. Clin Genet. 1982;22:102-4.

16. Callen DF, Woollatt E, Sutherland GR. Paracentric inversions in man. Clin Genet. 1985;28:87-92.

17. Fryns JP, Kleczkowska A, van den Berghe H. Paracentric inversions in man. Hum Genet. 1986;73(3):205-13.

(C) 2013 Pellegrini et al.; This is an Open Access article distributed under the terms of the Creative Commons Attribution License (http://creativecommons.org/licenses/by/3.0), which permits unrestricted use, distribution, and reproduction in any medium, provided the original work is properly cited.

Peer-review history:

The peer review history for this paper can be accessed here: http://www.sciencedomain.org/review-history.php?iid=194\&id=12\&aid=1015 